\title{
Large Data Change in International Relations and Its Challenges
}

\author{
Jun Du \\ Ningxia Normal University, Guyuan, Ningxia, 756000
}

\begin{abstract}
Keywords: International Relations; Large Data Age; Cross-Border Collection; Strategic Layout; Cloud Computing
\end{abstract}

\begin{abstract}
With the development of the times and the progress of science and technology, intelligent equipment and video equipment in the major industries are becoming more and more popular, at the same time accompanied by the rapid development of cloud computing and socialization, large data age has been blowing toward us, in the process of international relations can not be excluded. For the time being, the Taoism of international relations research is mainly embodied in three aspects. The first is the large data involved in the study of international relations related to the settlement of the controversial issues. It is followed by the misunderstanding of large data applications. Finally, cross-border data collection and cross-border flow problems. Through the past, a large number of practical results show that large data involved in international relations has become a thing to do. It is worth noting that if you want to use the big data must face two major problems. The first is to correctly understand the true meaning of large data, nature, through a variety of ways to minimize data noise. The second point is to face the data cross-border collection process of legal and political issues related to the data on the sovereign properties must be carefully analyzed. In order to clarify this problem, this paper will first elaborate on the specific meaning of large data in international relations, followed by careful study of the international relations to the era of large data, and then talk about the era of large international relations, the new challenges, hoping to get Some reference and reference.
\end{abstract}

\section{Introduction}

As we all know, in the twenty-first century we have entered the era of data security, data and its impact everywhere, from business to science, from government to art without exception. It is now necessary to have sufficient data resources that could greatly contribute to a new round of industrial revolution driven by data plants. Especially in the cloud computing as the premise of the big data has great possibilities to lead the commercial, scientific and other areas of the revolutionary breakthrough, a new era of large data has emerged. For example, too much noise or data noise response technology to be improved to a large extent will reduce the value of data cannot effectively dig out from the big data in the real value and so on. But there is no doubt that we live in the era of large data, large data has become the original means of production, has become a balance of economic and social value of the new resources on the daily generation of massive data efficient use has become a national access to information the core of the right, we can see that the big data problem should become an important issue in the study of international relations.

\section{The Possibility of Large Data Involved in International Relations}

Nowadays, all countries are looking at the social science disciplines, and the great data are spread in a revolutionary methodology and epistemology. In this context, the field of international relations research is also in which, but also around the large data can intervene in large areas of international relations research and lead to change and other issues have more controversy. First, the big data science revolution said. Refers to the big data is changing our way of life, through Google, Twitter, FACEBOOK, micro-blogging and other new media platform to capture and calculate the corresponding data, political research can be the first time to track the big city to see activities, clear international Strategic risk, but also can predict and alert the population to help quickly develop 
international scientific decision-making and accurate political marketing. The second is the big data application risk said. Refers to the development of their value, large data in the field of political science and international relations in the application of more prominent risk, why do you say so? Because the situation of the international situation of the overall situation is bound to involve cross-border data mining and cross-border movement, regardless of whether a country has the right to cross the sovereignty of the border mining and use of other countries, data from the technical point of view, once the big data into an international decision and diplomatic execution of the norm, then the data technology weak countries there is a great possibility of being technically strong country spy and mercy. It refers to the fact that large data does not necessarily lead to new insights into the diplomatic strategy of the international situation, and will not lead to revolutionary changes in political judgment and diplomatic decision-making patterns. The reason is that even if there is a large amount of structured and unstructured data can not be time and geographical constraints of the seizure in the international political areas of national security considerations and the protection of individual privacy, will be combined with the actual situation set the corresponding legal threshold And technical barriers, through this way to prevent the spread of data in the world at random. In addition, the fact that, with the larger the amount of data, the data itself will be the greater the noise, the development of the value of the data itself will be lower and lower. From this level, the large data will be difficult to be a field of international relations research and epistemological revolution.

\section{The Significance of Large Data in International Relations}

From the previous description, we can clearly see that large data as a revolutionary phenomenon has affected all aspects of human social development and the data has become the future to support national security and sustainable development of the important strategic resources, but also become an international relationship need to focus on the new areas of competition. In general, the transformative significance of large data to international relations can be manifested in three aspects: first, the economic value of the business determines the new national strength around the large-scale competition. The second is the safety, large data mining brought about by the predictive function of the future national strategic capacity as an important pillar. The third is sovereign, can be used as information carrier of large data is an important prerequisite for data sovereignty.

In this regard, it can be analyzed from the following levels. The first is that the data has great possibilities to become the largest trading commodity in the future. In other words, which business in the hands of valuable data resources will be able to produce better benefits. In particular, data cross-reuse can make large data into a large industry, as if the infrastructure construction industry, large data industry will be data providers, regulators and managers and other parties together. Followed by uncle will be born to data assets as the center of a variety of business models. For example, exogenous, endogenous, product type and cloud computing service type and so on. And we have good reason to believe that in the near future a pyramid-shaped industrial chain based on cloud computing - large data development - the application of various professional applications, a new scientific and technological revolution to promote the development of the world economy came into being. In such a large environment only those who use large data for real-time decision-making enterprises or institutions to flourish, those who can not adapt to this era of transformation of enterprises or institutions will gradually die. Finally, large data will be with the data mining technology continues to improve, and monetary and gold will become a new economic assets. Large quantities of enterprises found themselves through business transactions generated scattered data will turn waste into treasure, as part of corporate assets. For example, e-commerce enterprises have the basic data and transaction information and logistics companies have the product of transport information. For the knowledge-based economy, large data is an inexhaustible valuable resource. 


\section{The New Era of International Relations under the Background of Large Data}

Although we can not conclude that there will certainly be a new world order supported by information and data, but one thing we must believe is that big data will surely become a new challenge for international relations in the twenty-first century. New data hegemony and transnational security threats will bring new pressures on equality and democracy in international relations.

International relations democracy is of great benefit to the promotion of new international relations that foster adaptation and development. And hegemonism must be opposed to the democratization of international relations. The real purpose of the democratization of international relations is that the affairs of various countries are dominated by themselves and that international affairs are negotiated on an equal footing by all countries. As we all know, big data is a new field of information technology development in the United States following supercomputers and the Internet, and developed countries such as Europe and Japan pay particular attention to the handling of massive data, but they have not risen to the national strategic level, the current US attempt to occupy the dominant position of large data technology, where can we see it? After analysis found that although the United States in some network index, such as permeability ranking relative to the backward, but WEB2.0 industry is very strong, almost all over the global market. Such as Google, FACEBOOK and other companies exist, leading to the opportunity to access the United States at any time anywhere in the world data. By storing a large amount of electronic data in the cloud, cloud computing has driven a new change in the structure of the authority, cloud computing makes hardware, software, content and more concentrated in the hands of a small number of Internet services, and the vast majority of these enterprises are in the United States, these services are very convenient to collect data.

Now an important goal pursued by the people of all countries is a just and rational new international political and economic order. An important prerequisite for achieving this goal is the equality, co-operation and democracy of international relations. However, the demand for equality of international relations in the era of large data is facing a great challenge, and there is a data gap between the wealthy and the poor. This relationship can not only be generated within a society, such as between individual users and business users, but also between countries. At present, the distribution of information industry in various regions of the world has already shown a gap between asymmetry and regional data. In this way, those entities with social privileges (including businesses and institutions) may further strengthen their privileges by creating data, but countries that are reluctant to participate in data creation activities are bound to be marginalized. In this regard, the data may lead to stronger ones. It should be emphasized that large data can not be equally open to all subjects, even if there are many subjects that do not have the ability to analyze or analyze the ability to meet the requirements, to social media information as an example. At present, only social media companies can really get huge social data, such as FACEBOOK work for anthropologists can obtain the data, but other scholars do not have this power. In addition, there are some companies that do not allow the use of relevant data or a small amount of open data, and even some companies sell these rights at high prices, which will inevitably produce inequality. It can be seen that the ability of countries to cope with large data challenges is high and low, and new data gaps remain there.

Cooperation will become the mainstream of international relations under the age of globalization. The value of large data is reflected in the large and comprehensive nature of the data. In view of this, it is likely that countries will be able to generate greater economic and social benefits if they are able to cooperate on large data. However, due to the existence of the interests of the interests of countries, countries have different data policies and the relevant data in the cross-border circulation is facing many security threats. Which cross-border data flow is an important threat to network security and information security, and the United States "prism" plan in the world and its security panic has been fully proved cross-border data flow problems in large data and cloud computing background especially prominent. The first is the cloud computing itself, the characteristics of the 
decision. Although the current number of countries on some of the important data of foreign storage and cross-border transmission is expressly provided, but the cloud computing makes these provisions can not be implemented in technology. Generally speaking, in the cloud data access is in the online state, at this time it is difficult for users to control their own way to withdraw data, so there is no way to ensure that the third party is the abuse of the data. And the international and decentralized nature of the cloud poses a more serious problem. In this case, in order to maximize the meet the different needs of users, cloud service providers tend to consider the network efficiency, technical constraints, legal and economic factors, etc., the use of different locations to complete the corresponding task cloud. In this way, the data will be transmitted between different countries, the location of the data storage is also difficult to determine, not only the country is difficult to guide the data in the cross-border transmission, even if the information data transmission I usually do not know what is going on, cloud data The disclosure of the problem is not uncommon, thus a serious threat to the privacy of individuals, corporate business secrets leak even for the country's sovereignty and security.

\section{Conclusion}

To sum up, with the development of science and technology and the progress of the times, large data has become a new challenge in international relations in the 21st century. Whether it is from the economic, security or sovereignty point of view, it is bound to play an indispensable key role. While the United States currently occupies a hegemonic position in the field of large data, but also gives other countries a golden opportunity, but China in the current cloud computing as the representative of the third IT industry in the big data industry and the global basic at the same starting line, China in the traditional information technology is difficult to get rid of the layout of cyberspace power structure. But China has the world's largest mobile phone users and Internet users and the network's second largest language, have sufficient capacity to support the Chinese-based technical standards. So China must be combined with their own situation from the top of the government design and large data management efforts, so that better data for the public services.

\section{References}

[1] Cai Cuihong. International data in the large data changes and challenges [J]. World Economy and Politics .2015

[2] Dong Qingling. Reflection on the application of large data in the study of international relations[J]. Exploration and Contention .2014

[3] Meng Zhiyuan; Lu Xiao; Hu Fangang. Study on the Theoretical Path and Application of Big Data Driving Education Reform - Analysis of the First China Education Big Data Development Forum [J]. Distance Education Journal .2015.

[4] Zhi Jichao. International system transition under the perspective of the construction of new Sino - US relations[J]. Jilin University .2014 